\title{
USO DA CELULOSE LIOFILIZADA EM LESÕES DE NERVOS PERIFÉRICOS COM PERDA DE SUBSTÂNCIA
}

\author{
Luis Renato Mello', Yanara Feltrin², Rafael Selbach', \\ Gilberto Macedo Junior ${ }^{3}$,Cleverton Spautz ${ }^{3}$, Leandro José Haas ${ }^{4}$
}

\begin{abstract}
RESUMO - O trabalho analisou a celulose liofilizada como invólucro de lesões de nervos periféricos, com perda de substância, investigando a intensidade de reação inflamatória e o alinhamento axonal. Dez cães foram divididos em 3 grupos: Grupo 1 - seccção e recolocação de $1 \mathrm{~cm}$ de nervo ciático; Grupo 2 - não recolocado fragmento seccionado; Grupo 3 - sutura epineural, sem invólucro celulósico. A recuperação motora iniciou na oitava semana, lenta e progressiva, sem recuperação total. A autópsia mostrou reação fibrótica ao redor da celulose e aderência ao plano muscular. Quando o enxerto foi recolocado, constatou-se continuidade do nervo com aumento de calibre local. Nos dez cães foi observada fibrose e regeneração neural variáveis na área de secção do nervo. Os grupos 1 e 3 mostraram coaptação entre cotos e enxerto. Concluiu-se que a celulose liofilizada provocou moderada reação fibrótica com realinhamento e crescimento axonal quando foi recolocado, como enxerto, o fragmento do nervo seccionado.
\end{abstract}

PALAVRAS-CHAVE: nervo periférico, trauma, celulose.

Use of lyophilized cellulose in peripheral nerve lesions with loss of substance

ABSTRACT - Lyophilized cellulose was analysed to verify the degree of inflamatory reaction and axon realignement in the sciatic nerve after loss of neural substance. Ten mongrel dogs were divided into: Group 1 - $1 \mathrm{~cm}$ section of sciatic nerve which was replaced at lesion site; Group 2 nerve section without fragment replacement. The section site was involved with lyophilized cellulose. Group $3-1 \mathrm{~cm}$ fragment section sutured epineurally. Motor response started at eighth week. Moderate fibrotic reaction to cellulose was seen in Group 1 and 2 animals. Groups 1 and 3 showed coaptation between the nerve and nerve graft with ongoing axons. In Group 2, 1 dog showed regrouth of axons through the empty space. It was concluded that lyophilized cellulose caused moderate fibrous reaction when implanted in peripheral nerve lesions with loss of substance; it can act as envellop protection in those lesions mainly if a neural graft is inserted.

KEY WORDS: peripheral nerve, trauma, cellulose.

O uso da microcirurgia para o tratamento das lesões dos nervos periféricos, determinou grandes avanços nos resultados funcionais pós-operatórios, persistindo no entanto diversos questionamentos relativos ao manejo ideal destas lesões. Vários fatores influenciam o tratamento, tais como o uso de técnica operatória adequada, a presença de tensão no local da lesão, a determinação correta do local acometido, o alinhamento adequado dos fascículos motores e sensitivos e a presença de processos cicatriciais impedindo a mobilização do nervo'.

A técnica microcirúrgica corretamente empregada é a aproximação dos cotos, com ou sem o uso de enxertos, sendo realizado sutura com fios monofilamentares não absorvíveis nos fascículos ou no epineuro ${ }^{1}$.

O uso de tubos, que atuam como invólucro permitindo a formação espontânea de uma matriz de fibrina, favorece o crescimento de axônios, capilares e células não neurais Muitos experimentos têm sido realizados usando-se invólucros ou colas nos cotos, em torno de suturas término-terminais, com a finalidade de prevenir a invasão de tecido conjuntivo no local do reparo, defendendo-o contra efeitos constritivos do tecido cicatricial externo ${ }^{1}$. Além da proteção, estes envelopes promovem regenera-

Estudo da Disciplina de Neurocirurgia, Curso de Medicina, Universidade Regional de Blumenau, Blumenau SC, Brasil: ${ }^{1}$ Professor Titular de Neurocirurgia; ${ }^{2}$ Acadêmica de Medicina e Bolsista de Iniciação Científica do PIBIC; ${ }^{3}$ Acadêmico de Medicina; ${ }^{4}$ Médico Residente em Neurocirurgia do Hospital Santa Isabel.

Recebido 21 Novembro 2000. Aceito 16 Janeiro 2001.

Dr. Luis Renato Mello - Rua Ferdinando Schadrack 29 - 89050-370 Blumenau SC - Brasil. 
ção axonal longitudinal, restringindo a expansão de neuromas ${ }^{2}$. Os principais produtos testados para este fim são: veias, tubos de colágeno, tubos de âmnion, teflon expandido (Gore-Tex), membranas sintéticas de silicone (silastic), cola de fibrina e condutos de ácido poliglicólico'.

O material ideal para este fim ainda não foi encontrado pois deverá ser totalmente reabsorvido após proteger o local lesionado por um período de 6 a 8 semanas, até que a extensão do axônio alcance o coto distal ${ }^{2}$.

Este experimento foi realizado com a finalidade de buscar uma substância alternativa que se adapte melhor ao uso como invólucro nas lesões de nervo periférico com perda de substância. Utilizou-se a celulose liofilizada com o propósito de verificar sua ação protetora em relação à proliferação tecidual no local da lesão e sua capacidade de promover o alinhamento axonal.

\section{MÉTODO}

Foram utilizados 10 cães adultos, entre $5 \mathrm{~kg}$ e $10 \mathrm{~kg}$, provenientes do biotério da Universidade Regional de Blumenau. A celulose pura foi obtida a partir da síntese de bactérias do gênero Acetobacter. submetida a processo de liofilização que modificou sua estrutura, tornandoa esbranquiçada e porosa. Não necessitou de cuidados específicos e, se necessário, poderia ser novamente esterilizada em autoclave ${ }^{3}$.

Os animais foram divididos em 3 grupos: Grupo 1 secção do nervo ciático recolocando um fragmento/enxerto no centro do envelope celulósico (4 animais); Grupo 2 - nervo ciático seccionado, retirado e não recolocado o fragmento/ enxerto no centro do envelope celulósico (4 animais); Grupo 3 - nervo ciático seccionado, recolocado o fragmento/enxerto de $1 \mathrm{~cm}$ e reconstituído por sutura epineural usando fio de nylon monofilamentar 7:0, com o propósito de estabelecer comparação, não sendo utilizada celulose como invólucro protetor.

\section{Procedimento cirúrgico}

Com prévia anestesia com cetamina posicionou-se o animal em decúbito ventral seguindo-se incisão longitudinal na coxa esquerda, região póstero - lateral, no sulco formado pelos músculos bíceps femoral e semi-tendíneo/ semi-membranoso, identificando e isolando o nervo ciático. Introduziu-se então folha de celulose padronizada em $4 \mathrm{~cm}^{2}$ de superfície abaixo do nervo e fixou-se o epineuro nos dois bordos da celulose com dois pontos de fio monofilamentar 7:0, com a finalidade de evitar que o nervo se deslocasse após sua secção. Posteriomente, seccionou-se o nervo em 2 níveis, a $0,5 \mathrm{~cm}$ de cada ponto de fixação na celulose, produzindo um fragmento livre de $1 \mathrm{~cm}$ no interior da celulose, que funcionou como enxerto (Figs 1 e 2). O envelope celulósico foi fechado em forma de tubo nos grupos 1 e 2 (Fig 3).

\section{Observação pós-operatória}

Os cães foram observados por 24 semanas, com teste clínico de percepção sensitivo - motora (pinçamento e agulhas ), com freqüência quinzenal, visando acompanhar a evolução da recuperação funcional do nervo ciático lesado. A avaliação foi baseada em graus de resposta conforme o seguinte protocolo : grau I - ausência de respostas ao estímulo; grau II - reação de retirada incompleta; grau III - reação de retirada completa.

Após este período os animais foram sacrificados, através da injeção de Thionembutal sódico intravenoso em bolo, enviando-se as peças anatômicas operadas para o Laboratório de Patologia CIPAC, em Blumenau, onde foram realizados o estudo histopatológico e a documentação fotográfica.

\section{RESULTADOS}

Avaliação funcional

Analisando os resultados obtidos, observamos que em todos os animais operados, não foram detectadas respostas sensitivas ou motoras consistentes até um período de aproximadamente 8 semanas. Após este período, a incapacidade motora passou a regredir e a resposta sensitiva permaneceu pouco perceptível até o término da pesquisa. Apesar do certo grau de recuperação motora apresenta$\mathrm{da}$, os movimentos foram sempre incompletos (grau II), permanecendo assim até o final do trabalho.

\section{Aspecto macroscópico}

Dois dos quatro animais do grupo II, deixados sem enxerto, não tiveram resultados satisfatórios em relação à técnica, havendo desprendimento do ponto de sutura entre o epineuro e a celulose, provocando deslocamento do coto distal. Um cão do mesmo grupo faleceu antes do término do período de observação, não sendo submetido a estudo macroscópico. No quarto animal sem enxerto verificou-se presença de tecido neural no espaço vazio entre os cotos. No entanto, neste animal não foi realizado estudo macroscópico e o resultado microscópico será demonstrado abaixo. Nos grupos 1 e 3, observou-se coaptação dos cotos proximal e distal ao enxerto. Após a retirada cuidadosa do envelope celulósico verificouse aumento de calibre, superfície lisa e continuidade do nervo, dificultando a visualização do local da secção (Fig 4). Foi observado, durante autopsia dos cães dos grupos 1 e 2 , reação fibrótica moderada ao redor do invólucro protetor celulósico, com certo grau de aderência ao plano muscular, havendo porém integridade da membrana, sem sinais macroscópicos de reabsorção.

\section{Aspecto microscópico}

O processo histológico foi realizado de acordo 
com as técnicas habituais, tendo sido realizadas as colorações de HE e tricrômio de Masson.

No grupo I, com recolocação de fragmento, evidenciou-se presença de filetes nervosos ao nível do ponto de contato entre os cotos e o enxerto. Nestes cães foi observado fibrose de discreta a moderada na área de secção do nervo, assim como discreta regeneração neural (Figs 5 e 6). No grupo 2 apenas um cão apresentou sinais microscópicos de presença de filetes nervosos entremeados por fibrose de intensidade moderada. Neste animal a celulose aumentou de espessura limitando a expansão natural da reconstituição nervosa por causar constrição(Fig 7). Em 2 cães não havia união entre cotos e enxerto, por deslocamento do nervo durante o pós-operatório, verificando-se apenas a presença de fibrose no envoltório celulósico, sem componente nervoso. Houve resposta inflamatória com formação de granulomas tipo corpo estranho nos animais cujo nervo foi envolto pela celulose (Fig 8). O grupo III, submetido a sutura epineural, demonstrou união entre os cotos, fibrose moderada com área de regeneração nervosa e escassa resposta inflamatória.

\section{DISCUSSÃO}

A tentativa de correção de lesões de nervos periféricos foi iniciada já no século dezoito com as experiências em animais realizadas por Cruikshank. No entanto o primeiro reparo epineural de nervos foi realizado por Baudens em 1836. A partir de estudos da estrutura dos nervos periféricos e da bainha de Schwann, progressivamente aumentou a compreensão dos fenômenos que interferem em sua regeneração 5 .

Diversos fatores como o local da lesão, duração, estado local da musculatura e presença de fibrose ou compressão extrínseca, interferem na recuperação do nervo. No entanto o grau da lesão é fundamental para avaliar sua melhoria. Lesões incompletas (axônio ou neuroapraxia) tem prognóstico diverso de lesões completas (neurotmese). A distância entre os cotos, provocada por neuromas distais com ou sem continuidade, geram espaço vazio entre os cabos proximal e distal, dificultando mais a correção cirúrgica ${ }^{5}$.

Diversos estudos constataram a dificuldade de regeneração nervosa após uma axotomia periférica, com diminuição do diâmetro da fibra regenerada, formação de uma bainha de mielina mais fina, e conseqüente diminuição da velocidade de condução ${ }^{6,7}$.

Para corrigir estas lesões a simples sutura epineural foi modificada por Seddon, que acrescentou a interposição de pontes de enxerto de nervos, método posteriormente aperfeiçoado por Smith que adicionou o uso do microscópio e agulhas de sutura menos traumáticas ${ }^{5}$. Este procedimento refinado, entretanto, demandava nova operação com retirada de outro nervo, aumentando a agressão ao paciente. Surgiu então a idéia de envolver a extremidade proximal e distal da lesão com tubos, visando proteção, reorientação e indução à regeneração das fibras As primeiras referências às lesões nervosas tubulizadas, vêm do século passado e inúmeros modelos experimentais se sucederan, buscando materiais inertes, flexíveis ,bioabsorvíveis, que não provocassem fibrose, isquemia, inflamação ou colapso local, além de permitirem o acúmulo de fatores de crescimento no local ${ }^{8}$.

No desenho deste estudo optou-se pela secção de $1 \mathrm{~cm}$ de nervo ciático, recolocando-o ou não, baseando-se nos achados de autores que indicavam ser a extensão de $1 \mathrm{~cm}$ adequada para se obter, com segurança, brotamento axonal e redirecionamento das fibras ${ }^{6,8,9}$.

Lundborg e cols. utilizando tubos de silicone em secções de nervo ciático de rato com espaço de $10 \mathrm{~mm}$ entre os cotos, obtiveram sucesso quanto ao crescimento axonal mas, em espaços maiores, observaram decréscimo da ação protetora destes tubos $^{9}$. A seguir descreveram um caso de reconstrução de um espaço de $0,5 \mathrm{~cm}$ do nervo ulnar no punho com um conduto de Silastic ${ }^{9}$.Mais recentemente estes autores realizaram enxerto com nervo bioartificial que consistiu em tubo de silicone com oito filamentos de poliamido (250um de diâmetro) no seu interior. Este nervo artificial foi usado experimentalmente em lesões de ciático de ratos com extensão de aproximadamente $15 \mathrm{~mm}$. Após 4 semanas demonstraram crescimento de fibras sensoriais em direção ao segmento distal do nervo. Também observaram mielinização axonal na matriz tecidual formada entre os filamentos sintéticos ao longo de todo comprimento do tubo. Em contraste, quando foi usado tubo de silicone sem os filamentos sintéticos em lesões com espaço de $15 \mathrm{~mm}$, observaram apenas a presença de fluídos e discreta formação tecidual. Concluíram que este nervo artificial poderia ser usado em lesões extensas $(15 \mathrm{~mm})$ de nervos periféricos ${ }^{10}$.

Buscando um tubo protetor ideal, absorvível, Kitahara e cols. implantaram tubo de colágeno em nervo facial de cães, deixando espaço livre de $5 \mathrm{~mm}$ entre os cotos do nervo. Após 8 semanas de pós-operatório, observaram, macroscopicamente, regeneração nervosa, sendo o segmento regenerado similar 


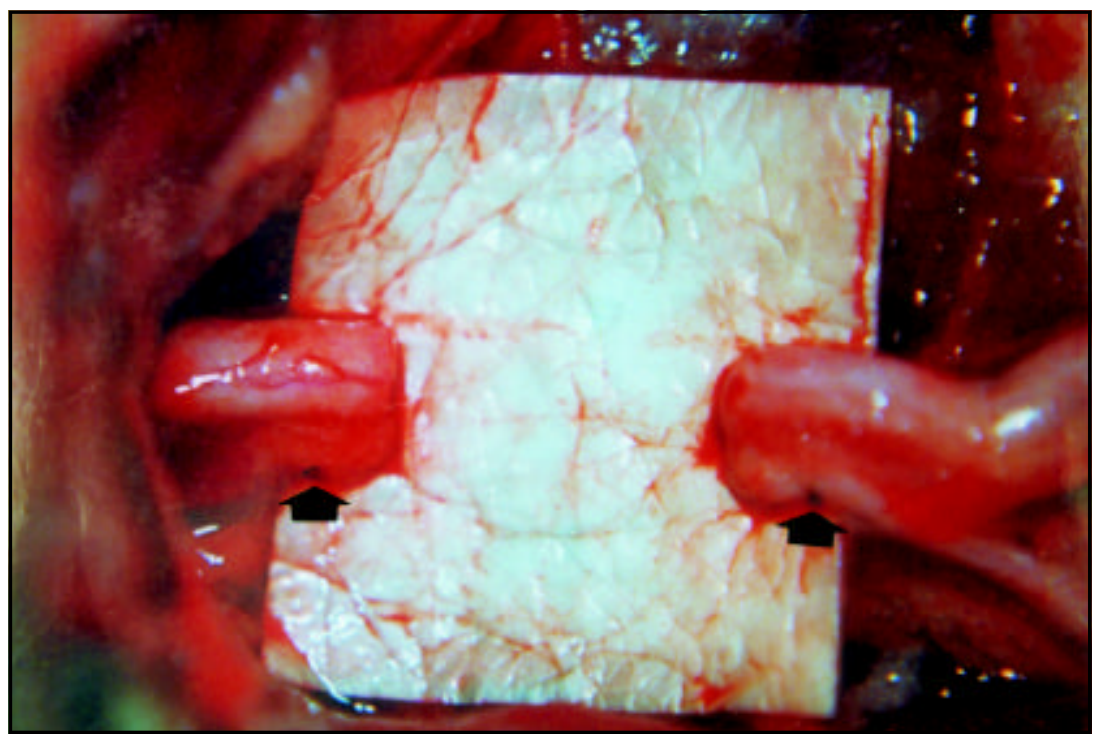

Fig 1. Detalhe da técnica cirúrgica com a celulose fixada ao epineuro por 2 pontos de fio mono-filamentar (setas), e a secção de 1 $\mathrm{cm}$ provocada no nervo ciático esquerdo.

Fig 2. Recolocação do enxerto retirado nos animais do Grupo 1
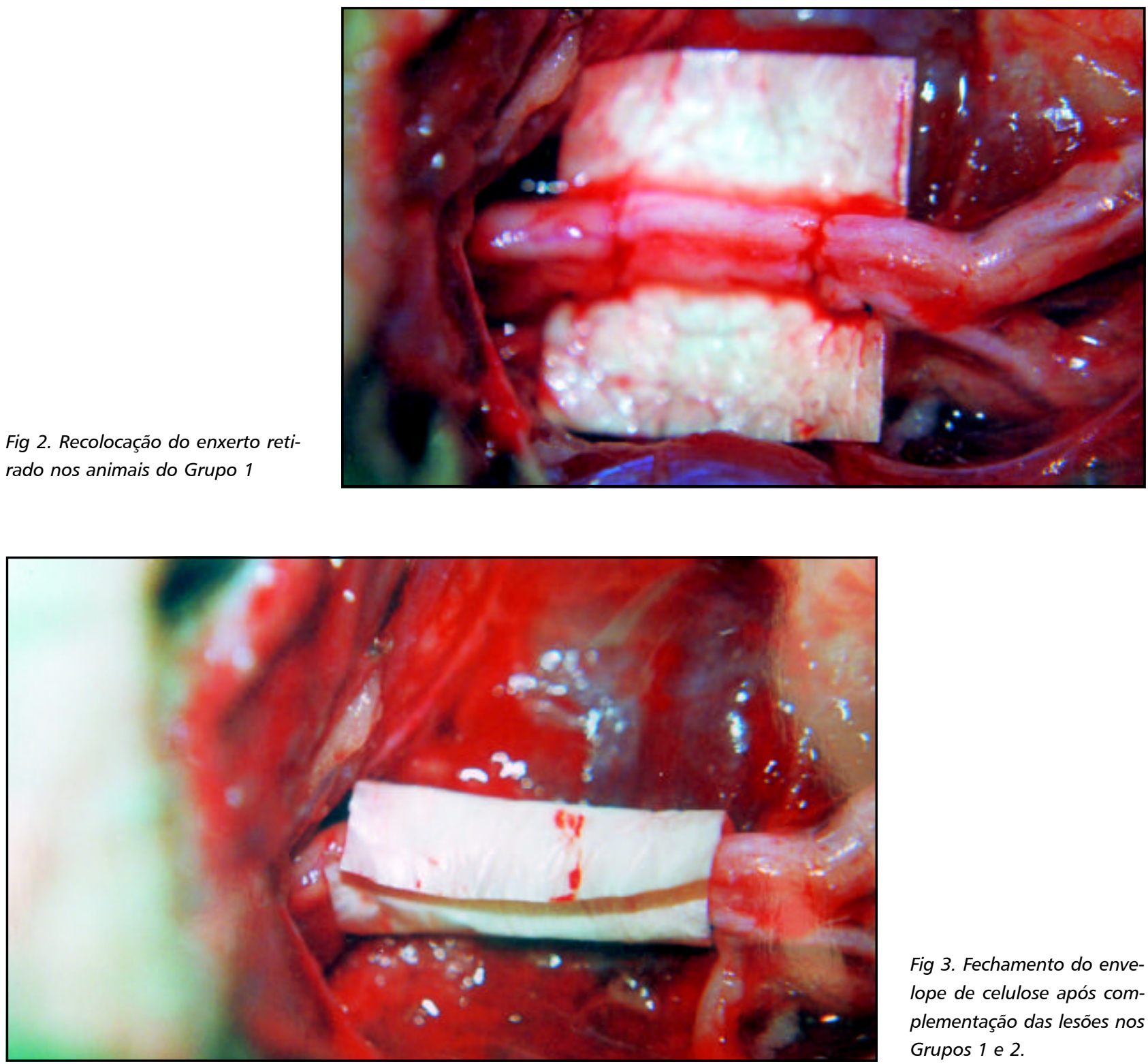

Fig 3. Fechamento do envelope de celulose após complementação das lesões nos Grupos 1 e 2. 


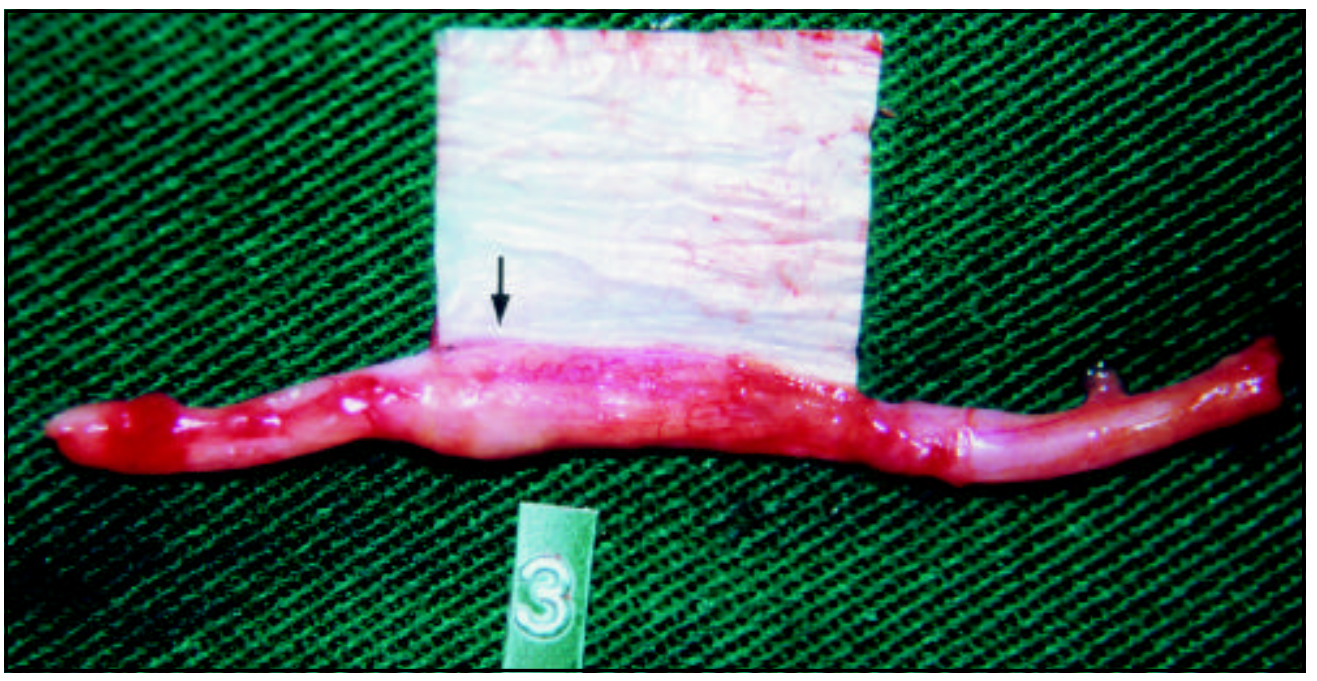

Fig 4. Cão 3, Grupo 2 - com enxerto - Resultado obtido após seis meses observando-se desaparecimento de solução de continuidade provocada pela secção, aumento de volume da região regenerada, em especial na porção proximal (seta).

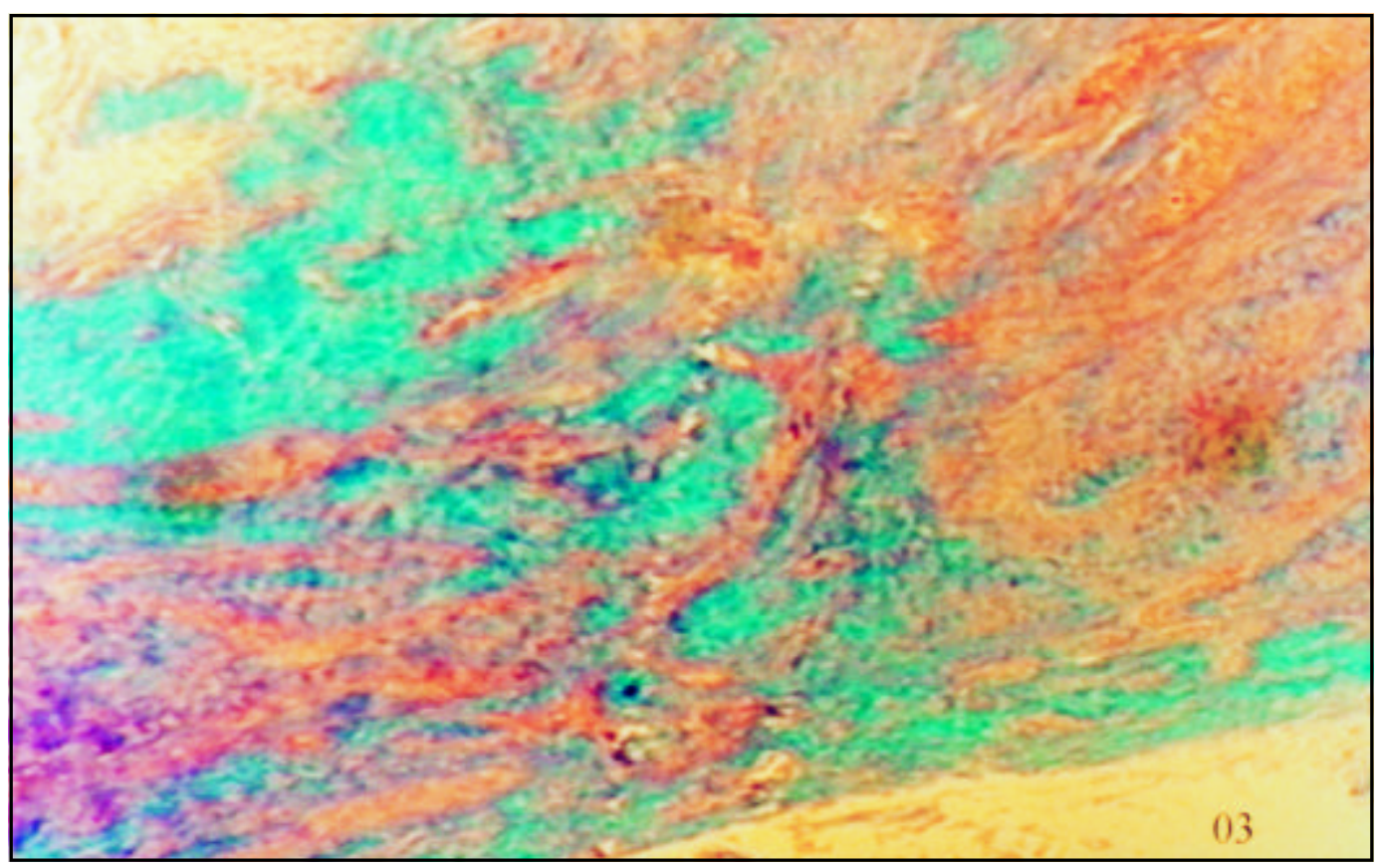

Fig 5. Cão 3- Grupo 1 - com enxerto - Corte histológico da área de união entre enxerto e coto neural, evidenciando fibrose moderada entre filetes nervosos regenerados. (Tricrômico de Masson - 40x).

em aparência aos cotos proximal e distal do nervo, porém com diminuição de calibre. O colágeno foi totalmente absorvido, sem haver sinais do tubo ${ }^{11}$.

Em nosso experimento, um dos cães do grupo 1, onde havia sido recolocado enxerto entre os cotos, a microscopia mostrou formação de realinhamento axonal no interior do envelope celulósico. A membrana estava espessada com redução relativa do calibre do neonervo. A possibilidade de ser demonstrada continuidade de axônio com o emprego exclusivo de microscopia óptica, foi prejudicada por este método não ser suficientemente acurado para seguir um axônio até o coto distal. Nos grupos 1 e 2 a celulose encontrava-se íntegra sem sinais macroscópicos de reabsorção.

A escolha da celulose como tubo protetor foi baseada na escassa reação fibrótica obtida pelo emprego deste material como substituto de duramáter em cães ${ }^{12,13}$. Outra razão foi o achado de partículas refringentes de celulose no citoplasma das células gigantes, em ratos que receberam implante de celulose no fígado, sugerindo absorção do material por fagocitose ${ }^{14}$. Observou-se neste experimento que a celulose provocou resposta inflamatória com 


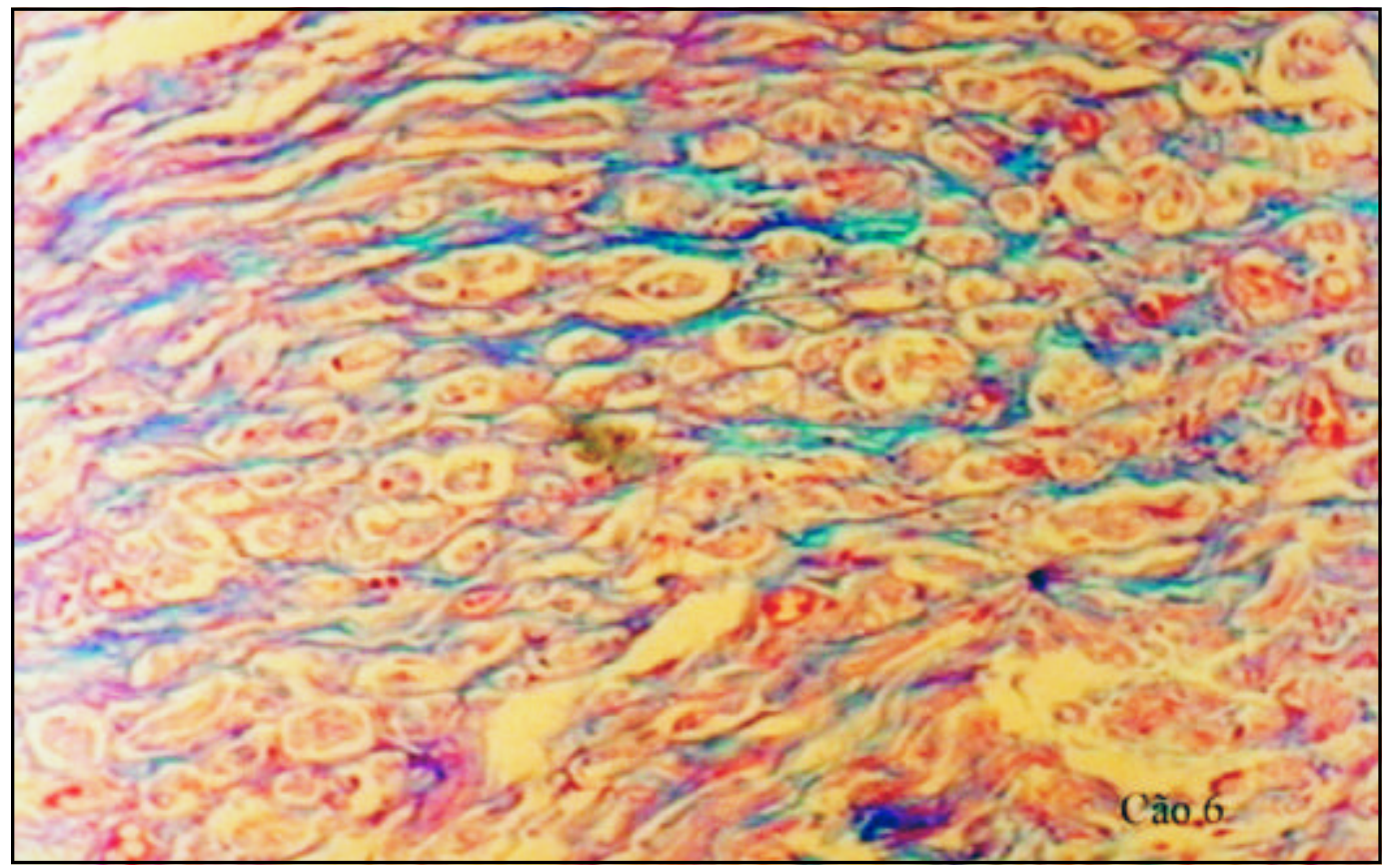

Fig 6. Cão 6 - Grupo 1 - com enxerto - Corte histológico evidenciando intensa regeneração e fibrose moderada em local correspondente ao enxerto. (Tricrômico de Masson - 400x).

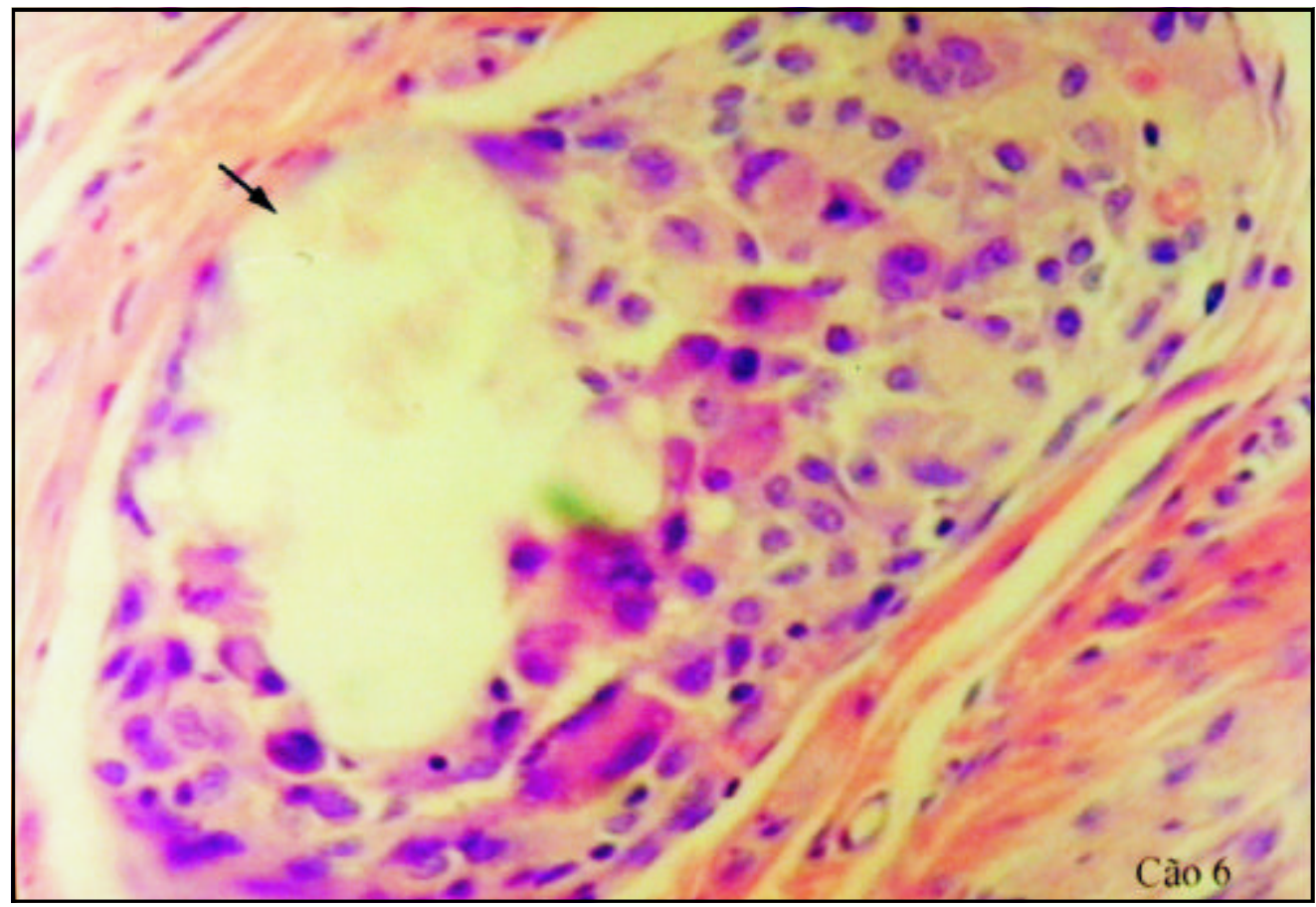

Fig 7. Cão 6 - Grupo 1 com enxerto - Corte histológico mostrando reação granulomatosa de tipo corpo estranho, envolvendo fragmentos de celulose (seta). (HE - 400x).

formação de numerosas células gigantes multinucleadas tipo corpo estranho nos animais cujo nervo foi envolto por celulose (grupos 1 e 2). Naqueles em que não foi utilizada a membrana celulósica (grupo 3) a presença de tecido fibrótico foi escassa. A presença de partículas de celulose no interior destas células não foi adequadamente pesquisada, sendo impossível afirmar ou negar uma possível reabsorção da membrana celulósica.
Outros materiais e técnicas de tubulização das lesões de nervos periféricos tem sido usados ao longo do tempo. Tindal e cols. relataram com sucesso a reconstrução de um espaço de $2 \mathrm{~cm}$ do nervo femoral com o uso de veia como invólucro protetor ${ }^{1}$ Na tentativa de prevenir o aparecimento de dor devido a cicatrização em lesões de nervos periféricos, Masear e Colgin utilizaram invólucro venoso em 119 pacientes. Obtiveram resultados satisfatórios em $79 \%$ dos 
Fig 8. Cão 2 - Grupo 2 Corte histológico mostrando fibrose discreta e regeneração neural observando-se presença de filetes nervosos de permeio à fibrose (seta fina), ocupando o espaço vazio entre os cotos proximal e distal. Aumento da espessura da celulose por tumefação, com compressão do filete nervoso (seta larga).

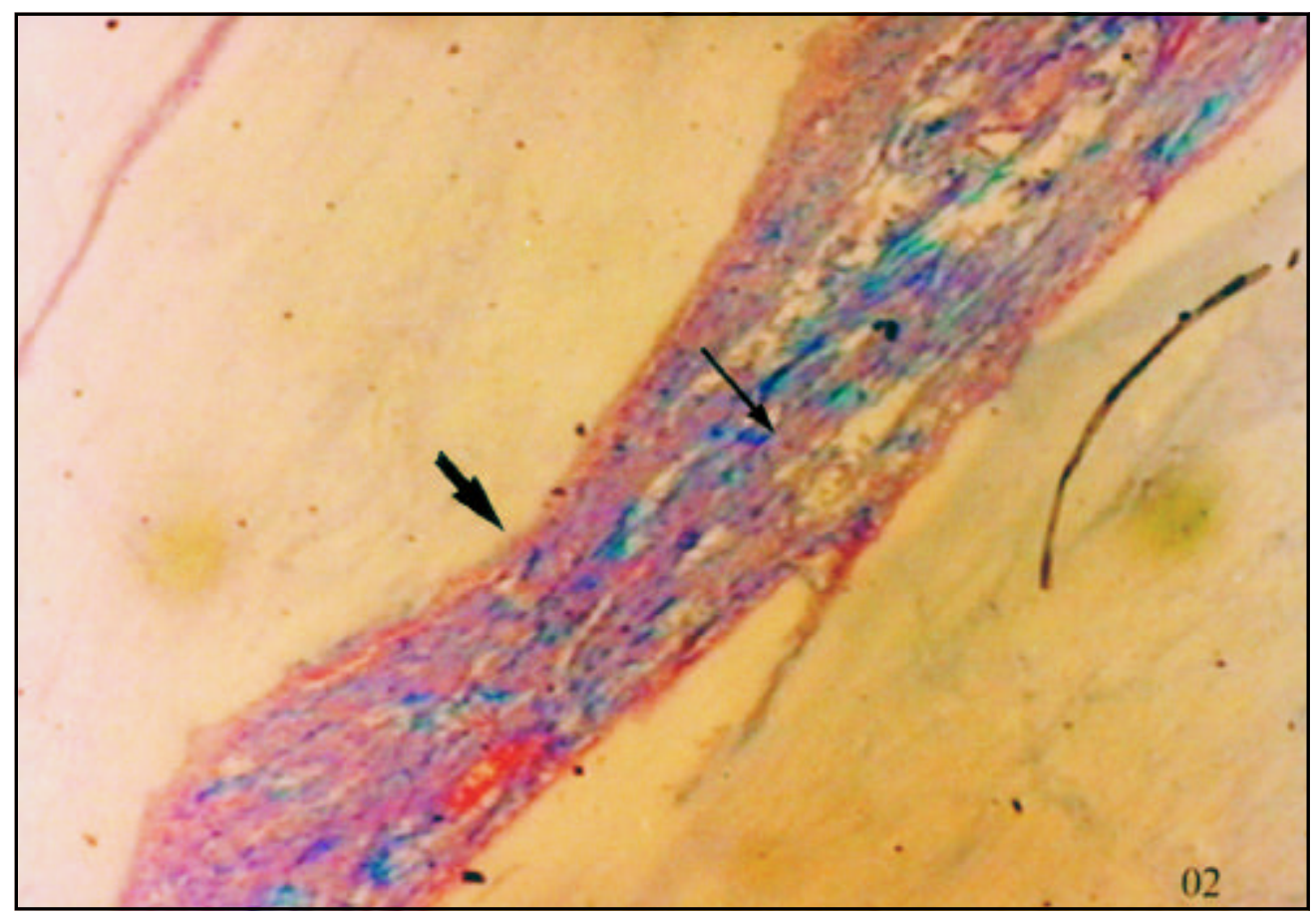

casos, com diminuição significativa da dor após observação de 25 meses, tendo como principal complicação a presença de infecção no local do reparo ${ }^{15}$.

Millesi observou que o uso de cola artificial de cianocrilato não tem valor para o tratamento de lesões de nervos periféricos ${ }^{16}$. Entretanto, a cola de fibrina poderia ser usada, por ter como base uma solução concentrada de fibrinogênio alogênico que se põe em contato com os fatores de coagulação, necessários para produzir a coagulação da fibrina. Em estudo comparativo entre a cola de fibrina e a neurorrafia com fio inabsorvível, concluiu-se que ambos os métodos oferecem resultados favoráveis na reparação dos nervos periféricos, havendo uma ligeira vantagem no uso da cola de fibrina, pela redução do tempo cirúrgico e sua maior praticidade ${ }^{17}$.

Mora e cols. empregaram cola de fibrina para reparar nervos periféricos em 62 pacientes tendo constatado recuperação sensitiva em $100 \%$ e recuperação motora de $63 \%$, em um período maior que 12 meses após a cirurgia ${ }^{17}$.

luan e cols verificaram os efeitos da cola de fibrina retirada do veneno de cobra do gênero Crotalus, aplicada na reparação do nervo ciático de ratos. Os resultados obtidos foram similares à cola de fibrina convencional, havendo presença de fibras nervosas no coto distal enquanto que o grupo controle apresentava somente fibrose local extensa e ausência de fibras nervosas ${ }^{18}$.

A realização de sutura epineural como grupo controle, na pesquisa aqui descrita, foi justificada por ser esta a técnica mais largamente utilizada na clínica, com o maior número de casos relatados.

Gama e cols. acreditam haver fortes indícios de que a regeneração sensitiva é pior que a motora apesar do trabalho discordante de Madorsky e cols e outros ${ }^{19-23}$.A explicação para este fato, é que após uma lesão nervosa periférica ambos os neurônios, motor e sensitivo, ficam privados dos fatores neurotróficos derivados dos órgãos alvo, dos quais depende a sobrevivência da célula nervosa. Os neurônios motores produzem de imediato seu fator específico a partir das células de Schwann, sobrevivendo assim à lesão axonal ${ }^{24}$. Já os sensitivos são mais suscetíveis à degeneração após a lesão, uma vez que a síntese dos seus fatores neurotróficos, por parte das células de Schwann é tardia, não sendo capazes de impedir a morte dos neurônios sensitivos dependentes destes fatores ${ }^{24}$. Demonstrou-se também, à microscopia, áreas de regeneração caracterizada por grupos de axônios organizados em minifascículos, característica do processo de compartimentalização, típico da regeneração nervosa periférica. Estes minifascículos eram envoltos pelo próprio perineuro, e vários destes conjuntos estavam unidos por um epineuro ${ }^{19,25}$.

Embora na maioria dos relatos clínicos a recuperação sensitiva preceda a motora, neste trabalho observamos recuperação sensitiva deficiente. A incapacidade motora passou a regredir apenas por volta da oitava semana. Apesar de certo grau de re- 
cuperação, os movimentos foram sempre incompletos e assim permaneceram até o final da pesquisa.

Para demonstrar a regeneração nervosa promovida por tubos de colágeno em nervo facial de ratos, Kitahara e cols utilizaram além de microscopia óptica (MO), a microscopia eletrônica (ME) que evidenciou muitas fibras regeneradas com axônios mielinizados e não mielinizados, circundados por intensa fibrose e tecido vascular. Observaram células de Schwann no local da regeneração. Complementaram com eletromiografia (EMG) que revelou, na terceira semana de pós-operatório, somente picos à estimulação elétrica, sem nenhum sinal de movimento de pálpebra. Na sexta semana a EMG demonstrou sinais iniciais de recuperação dos movimentos de pálpebra e a atividade elétrica registrada foi quase igual a dos cães não operados ${ }^{11}$.

Por dificuldade técnica no presente trabalho não foram utilizados a EMG e a MO para avaliação da recuperação funcional. Com parâmetros eletrofisiológicos os resultados funcionais seriam mais adequadamente monitorados, em especial, em relação à resposta sensitiva. Esta etapa está sendo atualmente realizada e será relatada futuramente.

\section{CONCLUSÃO}

Os resultados deste estudo mostraram que a proteção com celulose liofilizada provocou moderada reação fibrótica nos tecidos subjacentes à lesão de nervo ciático com perda de substância. No que se refere à crescimento axonal, houve realinhamento e crescimento axonal através da lesão provocada quando, além da proteção com celulose foi adicionada recolocação de fragmento neural seccionado como enxerto. Em um dos quatro animais em que não se adicionou enxerto houve comprovação consistente de crescimento axonal através do invólucro celulósico.

\section{REFERÊNCIAS}

1. Tindal GT,Cooper PR,Borrow DL.The practice of neurosurgery. Baltimore: Williams and Wilkins,1996:2885.
2. Youmans JR. Neurological surgery .3Ed.Toronto: Saunders Co,1990: 2496.

3. Mello LR, Feltrin LT, Fontes Neto PTL, Abreu A R. Estudo experimental da celulose biossintética para substituição de dura-máter e proteção cerebral. J Bras Neurocirurg 1995;6:38-45.

4. Massone F. Anestesiologia Veterinária.2Ed.Rio de Janeiro: Guanabara Koogan,1994: 107.

5. Spinner M. Injuries to the major branches of peripheral nerves of the forearm.2Ed.Toronto: Saunders Co,1978, 278.

6. Fields RD, Ellisman MH. Axons regenerated through silicone tubes splices. Exp Neurol 1986;92:48-74.

7. Schroder JM. Altered ratio between axon diameter and myelin sheat thickness in regenerated nerve fibres. Brain Res 1972;45:49-65.

8. Fields RD, Le Beau JM, Longo FM, Ellisman MH. Nerve regeneration through artificial tubular impants. Prog Neurobiol 1989;33: 87-134 .

9. Lundborg G, Dahlin L, Danielsen N. Nerve regeneration in silicone chambers: influence of gap length and of distal stump components. Exp Neurol 1982;76:361-775 .

10. Lundborg G, Dahlin L, Dohi D, Kanje M, Tereda N. A new type of "bioartificial" nerve graft for bridging extended defects in nerves. J Hand Surg 1997;22:299-303

11. Kitahara AK, Nishimura Y, Shimizu Y, Endo K. Facial nerve repair accomplished by the interposition of a collagen nerve guide. J Neurosurg 2000;93:113-120 .

12. Mello LR , Feltrin LT ,Fontes Neto PTL, Abreu AR. Duraplastia com celulose biossintética - estudo experimental. Arq Bras Neurocirurg 1996;15:14-21.

13. Mello LR, Feltrin LT, Fontes PTL Neto, Ferraz FFP. Duraplasty with biosynthetic cellulose: an experimental study. J Neurosurg 1997;86:143150 .

14. Mello LR, Machado FCH, Haas LJ, et al.. Efeitos hemostático e estrutural da esponja de celulose liofilizada. Arq Neuropsiquiatr 1998;56:613-620.

15. Masear VR, Colgin S. The treatment of epineural scarring with allograft vein wrapping. Hand Clin 1996;12:773-779.

16. Millesi H. Desarrolo reciente en la cirugia de los nervios periféricos. Rev Chil Cirurg 1987;39:98-102.

17. Mora JGG , Perez W, Chacon M, Mora CHG. Estudio comparativo entre la cola de fibrina y la sutura no reabsorbible como técnica de la reparación de nervios periféricos seccionados. Rev. Soc Med Hosp S Juan Dios 1988;9:49-50.

18. Iuam FC, Thomazini IA, Gianini MJM, et al.. Reparation of peripheral nerves with fibrin glue prepared from snake venon. São Paulo Med J 1995;113:1000-1002.

19. Gama SAM, Mattar JRR, Silva CF, Lainetti RD. Estudo experimental comparativo da ação das neurocinas cardiotrofina-1 e oncostatina-m na regeneração nervosa periférica. Acta Ortop Bras 2000;8:55-69.

20. Madorsky SJ, Swett JE, Crumley RL. Motor versus sensory neuron regeneration through collagen tubules. Plast Reconstr Surg 1998;102: 430-436.

21. Gordon T, Stein RB. Time course and extent of recovery in reinnervated motor units of cat triceps surae muscles. J Physiol 1967; 323:307-327.

22. Schmalbruch $\mathrm{H}$. Loss of sensory neurons after sciatic nerve section in the rat. Anat Rec 1987;219:323-329.

23. Lainetti RD, Pereira FC, Silva CF. Reduced sensory neuron regeneration by C57BL/6J mice. Br J Med Biol Res 1995;28:781-785.

24. Ljungberg C, Novikov L, Kellerth JO, Ebendal T, Wiberg M. The neurotrophins NGF and NT-3 reduce sensory neuronal loss in adult rat after peripheral nerve lesion. Neurosci Lett 1999;262:29-32 .

25. Dobrea GM, Unnerstall JR, Rao MS. The expression of CNTF message and immuno re-acitivity in the central and peripheral nervous system of the rat. Dev Brain Res 1992;66:209-219. 